\title{
Exposures in Aquatic Ecosystems: The Weak Link in Risk Assessments - A Critical Perspective
}

\author{
Burton, JR., G.A. \& Nedrich, S.M. \\ School for Environment \& Sustainability, Department of Earth \& Environmental Sciences. University of Michigan. \\ Ann Arbor, Michigan USA 48109-1041
}

Received October 13, 2017; Accept October 17, 2017

\begin{abstract}
The foundation of assessing risk for both humans and wildlife is understanding the connection between exposure to stressors and the resulting adverse effects on life. Humans and wildlife are surrounded by a plethora of stressors in human-dominated ecosystems. Most of these stressors do not pose a threat because the exposures to adverse effect levels do not occur or occur only briefly. While the practice of risk assessment has advanced significantly in the past three decades, it still has a number of shortcomings related to our inability to characterize exposures. Widely accepted traditional monitoring and assessment methods continue to be used, which focus on measuring chemicals in water and occasionally sediments or tissues at a small number of sites, then draw conclusions on risk to biota assuming exposures are constant. Spatial and temporal variation are a dominant component of aquatic ecosystems for stressors and biological receptors. The practicality associated with characterizing these exposures and receptor movements must and can be effectively addressed to provide decision-makers with scientifically-based evidence of exposure. More accurate and cost-effective options are described for future improvements in risk assessments.
\end{abstract}

Keywords: Ecological risk assessments, Contaminant exposures, Environmental epidemiology, Environmental forensics.

\section{THE ISSUE}

It has long been known that ecological risk assessments suffered from weak spatial and temporal characterizations of stressor exposures and effects (Dale et al., 2008; Burton \& Johnson, 2010). The U.S. EPA Science Advisory Board articulated how risk assessments could be improved ten years ago. Unfortunately, their recommendations have largely been ignored and not incorporated into standard practice. Perhaps this is due to managers assuming these were not cost-effective options. Ecological assessments that have strategically defined spatial and temporal characterizations of exposures and effects are limited. The typical practice is to collect a few water, sediment and biota samples from a site (not always together) and then linking chemical concentrations from those samples to biological responses (as varied as genomic markers to community alterations). This approach can work effectively at sites where the contamination is severe and widespread, but not at sites where there are patchy distributions of severe contamination and refugia for organisms to avoid the contamination.

These and other challenges with the traditional approaches have been described for sediment guidelines (Burton, 2017a). These challenges include the concurrent role of organism effects stemming from common stressors such as degraded habitat, altered flows, elevated temperatures, sedimentation and embeddedness, and elevated nutrients. These co-occurring stressors have long been recognized as causes of biological impairments, but nevertheless, are often ignored in favor of focusing on metal and synthetic organics as the primary stressors.

Every assessment method has its strengths and limitations, whether it be chemical characterization, passive chemical sampling, indigenous biotic community analyses, toxicity testing, tissue residues (and bioconcentration/ bioaccumulation) of contaminants, food web modeling, environmental quality guidelines/criteria or habitat analysis. 


\section{PCB SQGs (Dicks Creek)}

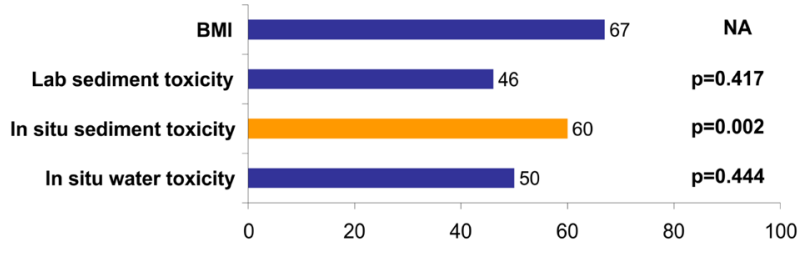

\section{Metal SQGs (Clark Fork)}

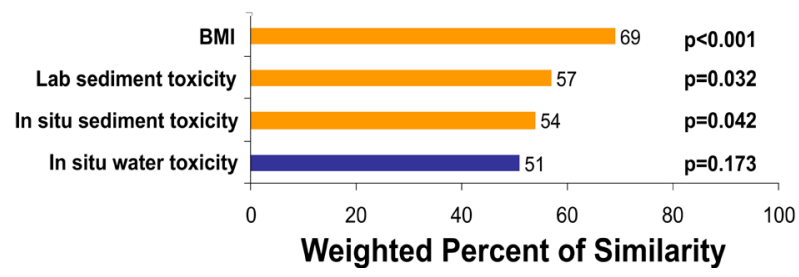

Figure 1. Agreement of four assessment methods (Lines-of-Evidence) with Sediment Quality Guidelines (SQGs) at two contamination sites. BMI = Benthic Mean Index.

Typical assessments may use one to three of these methods and they are often described as "Weight-of-Evidence" studies (Burton et al., 2002). Nevertheless, no one "line-of-evidence" (LOE) is sufficient for assessing ecological status. Each provides unique information that none of the others listed provide. Not having the information from any one LOE, thereby introduces uncertainties into the risk assessment process (Burton, 2017b).

So - if we are not doing an adequate job of characterizing ecological risk, then how can it be improved in a reasonable manner not requiring huge resources? The objectives of this paper are to: 1) Remind assessors to better link exposures with effects considering realistic scenarios; 2) Show how exposure can be misinterpreted if bioavailability and spatial/temporal issues are ignored; and 3) Describe an effective process for improving risk assessments in the future.

\section{CASE EXAMPLES: "EXPOSURES" MISINTERPRETED?}

When conducting literature reviews for an ERA, one easy way to misinterpret results is by overlooking provided food sources and exposure pathways. For instance, try using $\mathrm{V}$ tissue concentrations as evidence of sub-lethal impacts. In one article, Hyalella azteca tissue concentrations of $\sim 9$ $\mu \mathrm{g}-\mathrm{V} \mathrm{gdwt}^{-1}$ were measured at surface water exposures of 1 mg-V L-1 (the $\mathrm{EC}_{10}$ ) (Jensen-fontaine et al., 2014); however, in another study, no sub-lethal effects are observed at tissue concentrations as high as $21 \mu \mathrm{g} \mathrm{gdwt}^{-1}$ with $<5 \mu \mathrm{g}-\mathrm{V} \mathrm{L}^{-1}$ in surface water (Nedrich et al., 2018). How can this be? The first experiment only included surface water exposure and feeding with a non-contaminated food source, while the second study included elevated-V sediment exposure with direct sediment feeding. While both experiments provide useful information about different exposure pathways (primarily inhalation vs. ingestion), the latter experiment is likely more appropriate for
H. azteca as it reflects an exposure pathway which mimics how benthic amphipods behave in the environment.

When using a "weight of evidence" approach, it is important to have at least two and preferably more lines of evidence that assesses realistic exposures. Criteria based on species-sensitivity distributions (SSD) or sediment quality guidelines (SQG) are insufficient for predicting exposure, as they are based on confined toxicity testing. One example of this is from a recent study which found bioturbation by amphipods can increase exposure of metals $(\mathrm{Cr}$ and $\mathrm{Zn}$ ) to bivalves in some sediment types (Remaili et al., 2016), although common toxicity tests do not include exposures with multiple-species interactions. In another recent study on the Laurentian Great Lakes, several field-specific variables led to overestimated toxicity in lab exposures, including (1) fluctuating surface water chemical composition, particularly dissolved oxygen, (2) increased trophic complexity (periphyton as a food source), and (3) site hydrology, including groundwater inputs, precipitation, water renewal times, and high site energy leading to sediment erosion/resuspension (Nedrich, 2017). These evidences suggest lab toxicity tests are not necessarily reflective of aquatic exposures.

A WoE study evaluated how well various lines-ofevidence agreed with sediment quality guidelines (SQGs) at three sites across the U.S. (Burton et al., 2002; Burton, 2017a). Benthic macroinvertebrate communities, in situ sediment and water toxicity testing were compared. The findings showed, in general, that each assessment method provided unique information, not necessarily agreeing with each other, of the SQGs (Figure 1). Why would one expect different assessment outcomes to necessarily agree with each other when they are measuring different exposures and effects, affecting different species? When they do all agree it usually means the site is highly contaminated, but otherwise one should evaluate the outcomes not as disagreeing; rather providing diagnostic information on the degree of stressor exposures and their respective effects.

\section{ADDRESS SPATIAL UNCERTAINTIES}

Environmental assessors typically focus on sites of concern, that is sites where chemical contamination is excessive. This makes sense, but can bias assessments of gradients, where decision making is most challenging concerning where remediation efforts should end. For example, if a river pool is contaminated below an industrial outfall effects can easily be established until the chemical concentrations lower below acutely toxic thresholds and a change in substrate occurs, such as in a riffle zone. In addition, fish and benthic macroinvertebrate numbers and distributions typically vary differently depending on their life history, age, feeding, and reproductive patterns.

In studies were spatial gradients of contaminants are measured, there is rarely discussion or investigation of spatially dependent impacts to aquatic biota (Imperato et al., 2003; Wilkinson et al., 2017). These studies, while 
effective at creating contaminant 'heat maps' and locating contaminant sources, fall short of linking those findings to exposure outcomes (Moreno-González et al., 2015). In one study that comes to mind, PCBs and PAHs were associated with higher TOC sediment and spatially characteristics were used to link the source to petrochemical processes (not pyrogenic) (Astrahan et al., 2017); however, did not mention whether higher TOC sediment would be more likely to have cascading trophic effects as compared to low TOC sediments. Spatial studies which carefully consider exposure pathways are needed to improve ecotoxicological understanding and protect sensitive aquatic biota.

If there are nearby refugia, then biota may escape contaminant exposures. If there are extreme flow or drought events, this will also affect their presence/absence. Finally, invasive species, predators and habitat will affect the distributions of indigenous biota. To the aquatic ecologist, this makes perfect senses, but often environmental assessors do not take these realities under consideration when linking exposure to effects.

A survey of all sediment contamination data in the United States (over 19,000 data points) by the U.S. EPA showed sediment contamination to be highly patchy in sampled streams (Burton, 2017b). Less than 1\% of reaches exceeded Probable Effects Levels, so most "contaminated" streams actually had large areas of clean sediments. Another study (unpublished data) found PCB concentrations in Housatonic River (Massachusetts) sediments varied 3 orders of magnitude across one centimeter. These sediments were a mixture of silt, sand, gravel and cobble in a fast-flowing stream - so the exposures to biota highly varied over small gradients. In addition, storm events resulted in substantial bed-load movement so that the spatial gradients were changing routinely through the year.

Biological receptors vary dramatically in their home ranges and seasonal distributions. Sediment remediation actions that remove contaminated sediments (often PCBs), have rarely been able to document a subsequent reduction in fish tissue concentrations of PCBs (National Research Council. 2007). This is likely because the fish being monitored at the site are moving in and out of the site and other sites that may be contaminated. Even carp - a common receptor of concern due to their benthic feeding and long thought to have a small home range - actually travel long distances over seasons to find better habitats and food sources. It has been recommended that caged organism studies are more effective for determining worst case exposure scenarios, in order to document exposures (National Research Council. 2007).

\section{ADDRESS TEMPORAL UNCERTAINTIES}

Stressors vary temporally as diurnal, seasonal, and pulsed events lead to natural variability or via external forcing by anthropogenic actions (contaminant releases, land use changes, groundwater extraction, etc.). A new uncertainty facing risk assessors is climate change, leading to more extreme weather, increased droughts and flooding, and temperature increases, which have already been observed to effect aquatic biogeochemistry (Nedrich \& Burton, 2017a; Wu et al., 2014). In recent studies, post-drought re-flooding of oxidized sediments was found to cause sub-lethal effects to growth of the indicator species, Hyalella azteca, through exceedances of $\mathrm{Zn}$ in porewater (Nedrich et al. 2018; Nedrich \& Burton, 2017b). As hydrologic regimes become more extreme, the fate, effects, and exposure pathways of stressors are likely to be altered in myriad ways.

Several recent studies show seasonality of concentrations of metals, microplastics, pharmaceuticals, herbicides and pesticides, and other contaminants of emerging concern (Fairbairn et al., 2015; Moreno-González et al., 2015; Nouira et al., 2013; Pose-Juan et al., 2015; Wilkinson et al., 2017). Most studies describe temporal changes of a few stressors without hypothesizing or measuring how such changes link to biological exposure. By doing so, they answer the question "what" and "when" (contaminants are present) but fail to answer "why" (does it matter). In one model study, microplastic density increased coincident with ichthyoplankton density from overlapping seasonal (salt wedge formation, rainfall) effects (Lima et al., 2015). This is an important finding for predicting plankton and zooplankton exposure to microplastics. Another classic example of seasonal dependent exposure pathways, is the role of periphyton (biofilm) on regulating metal bioavailability and altering exposure (uptake) of organisms during summer months (De Schamphelaere et al., 2004; Morris \& Meyer, 2006). These types of studies are extremely helpful in pinpointing temporal variables which affect stressor exposure pathways and should be encouraged.

Biological receptors experience stressors on varied temporal scales, leading to uncertainties when predicting exposures. The timing of when organisms become exposed, whether it be in larval stages, during adulthood, or reproduction, can impact different biotic endpoints. In one recent study, exposure of gastropod egg sacs to low doses of $\mathrm{Cd}\left(\leq 10 \mu \mathrm{g} \mathrm{L}^{-1}\right)$ was shown to negatively impact gastropod growth and clutch size, while decreasing hatching success of the subsequent generation (Kimberly \& Salice, 2014). Exposures during juvenile and adult phases likely lead to different outcomes than during prenatal life histories, and in this example, showed gastropods (and likely most species) have greater sensitivity to $\mathrm{Cd}$ during prenatal exposure.

\section{STRATEGICALLY LINKING ASSESSMENT APPROACHES: LINES OF EVIDENCE}

As mentioned above in the Case Examples, the various LoEs available for assessing aquatic ecosystem quality are each measuring unique properties of the ecosystem. By including several LoE in a strategic manner, it allows for a highly diagnostic approach that reduces the uncertainty of the outcomes; thereby, enhancing its usefulness in decisionmaking. For example, LoEs could be categorized as measuring effects, exposure, or site characterization (Table 1). A strategic 
WoE design would be linking exposure with effects taking site characterization into account. This follows a classic ecological risk assessment paradigm (Dale et al., 2008). In order to best design a WoE assessment, the appropriate expertise must be involved to ensure, not only they are performed appropriately, but the results are interpreted correctly. For example, river site characterization would be incomplete without both high and low flow conditions being assessed. This would benefit from expertise in hydrology, stream ecology, aquatic chemistry and ecological modeling to best integrate the exposures with biological effects under both stable and dynamic conditions. Key questions to consider may be: When are the periods of the year when the indigenous communities are most susceptible to stress? What are the food web interactions and potential keystone species? Does resuspension of contaminants impact the biota of a stream? Are traditional laboratory surrogates of toxicity appropriate at the site of concern?

Unfortunately, this means bringing a greater diversity of expertise into the assessment and monitoring process but, in turn, this reduces the uncertainties associated with environmental assessments and increases the chance of effective decision-making.

\section{AN EFFICIENT PATH FORWARD}

The above discussions create the notion of requiring extensive resources and expertise to address the complexity of aquatic ecosystem assessments. If this is true, then improving assessments will not be feasible for most. So, let's consider an approach that is more efficient and thereby more allowing for more effective assessments of aquatic ecosystem quality. Tiered approaches are a logical path forward (Burton, 2017a; Burton, 2017b; Burton et al., 2005). The focus and outcome of managing and restoring aquatic systems should be to protect aquatic life and beneficial uses; then Tier 1 should start with the biology. Are the receiving waters healthy? Do they have pollution tolerant or sensitive communities? If the communities are tolerant of pollution, then Tier 2 can begin to characterize the site; such as are contaminants present in the water and sediment and is the habitat degraded? Tier 3 could be a more diagnostic and tease out which stressors are most important with more advanced site testing, possibly involving the use of passive sampling devices, exposing caged organisms to surface waters, ground-water surface water interactions, sediments, effluents, high flow conditions, etc. All of these would mandate comparisons with appropriate reference condition. For example, in urban watersheds, the appropriate reference condition is an urban watershed, not a pristine forested watershed. Effective assessments should document stressor exposures (all dominant stressors), the possible role of nearby refugia, and understanding the homerange of receptors (where are they exposed).

There are a number of research needs to make the path forward more productive and better improve aquatic ecosystem assessments. These needs could include:

- Mixtures and multiple stressors (organisms exposed to multiple stressors - have multiple exposures. Single chemical criteria do not account for multiple exposures.

- The preoccupation of acute vs. chronic thresholds (derived from clean laboratory and constant exposures) does not extrapolate well to in situ exposures. We need to understand that in situ exposures are usually with a plethora of ligands that reduce chemical bioavailability and that exposures vary in duration, frequency and duration. Since we cannot well characterize or model those 3 components of exposure, we must rely on in situ exposures, indigenous communities, and use experimentally designed assessments to tease out significant exposures and ecological effects.

- Finally, we need a greater understanding of the role of contaminated food (e.g., periphyton, sediments, prey) and their major routes of exposure, i.e. sediment vs. porewater vs. surface water AND ingestion vs. filtration/inhalation. (De Schamphelaere et al., 2004).

In summary, the assessment of water and sediment quality and ecological risk should rise to the next level of certainty and focus on better linking actual exposures of organisms with adverse effects. The old way of simply collecting grab samples of water, sediment and biota in close proximity to each, at one point in time - simply is inadequate unless the site is heavily contaminated. Human dominated sites contain a myriad of physical, chemical and sometimes biological stressors that must be considered to determine which stressor(s) are dominating. This then allows for effective decision-making for environmental managers. Spatial and temporal variation are a dominant component of aquatic ecosystems for stressors and biological receptors. There are now more accurate and costeffective assessment options that can be strategically linked allow for diagnostic, WoE-based approaches. The practicality associated with characterizing these exposures and receptor movements must and can be effectively addressed to provide decision-makers with scientifically-based evidence of exposure.

Table 1. Key Elements for Determining Environmental Risk or Hazard: Lines-of-Evidence to Integrate for Smart Weight-of-Evidence Assessments.

\begin{tabular}{lc}
\hline Category & Examples of Line-of-Evidence Measures \\
\hline Site Characterization & Habitat descriptors; Hydrology; Physicochemical parameters \\
Exposure & Tissue residues; Biomarkers ("nomics", enzymatic), Fate models \\
Effect & Toxicity; Biotic indices of structure and function; \\
& Toxicity-based water and sediment quality criteria \\
\hline
\end{tabular}




\section{LITERATURE CITED}

Astrahan, P., Silverman, J., Gertner, Y. \& Herut, B. 2017. Spatial distribution and sources of organic matter and pollutants in the SE Mediterranean (Levantine basin) deep water sediments. Mar. Pollut. Bull. 116(1-2): 521-527. https://doi.org/10.1016/j. marpolbul.2017.01.006.

Burton, G.A., Chapman, P.M. \& Smith, E.P. 2002. Weight-ofEvidence Approaches for Assessing Ecosystem Impairment. Hum. Ecol. Risk Assess. An Int. J. 8(7): 1657-1673. https://doi. org/10.1080/20028091057547.

Burton, G.A. Jr. 2017a. Breaking from Tradition: Establishing More Realistic Sediment Quality Guidelines. Environmental Science and Pollution Research. 1-6. https://doi.org/10.1007/s11356016-8338-x.

Burton, G.A. Jr. 2017b. The focus on chemicals alone in human dominated ecosystems is inappropriate. Integr Environ Assess \& Mgmt.13(4): 568-572. https://doi.org/10.1002/ieam.1929.

Burton, G.A. \& Johnston, E.J. 2010. Assessing contaminated sediments in the context of multiple stressors. Environ Toxicol Chem. 29(12): 2625-2643. https://doi.org/10.1002/etc.332.

Chapman, P.M. 2016. Environmental quality benchmarks - the good, the bad, and the ugly. Environ Sci Pollut Res. 1-4. https:// doi.org/10.1007/s11356-016-7924-2.

Dale, V.H., Biddinger, G.R., Newman, M.C., Oris, J.T., Suter, G.W., Thompson, T., Armitage, T.M., Meyer, J.L, Allen-King, R.M., Benfield, E.F., Burton, G.A., Chapman, P.M., Conquest, L.L., Fernandez, I.J., Landis, W.G., Master, L.L., Mitsch, W.J., Mueller, T.C., Rabeni, C.F., Rodewald, A.D., Sanders, J.G. \& van Heerden, I.L. 2008. Enhancing the ecological risk assessment process. Integr Environ Assess \& Mgmt. 4(3): 306-313. https:// doi.org/10.1897/IEAM_2007-066.1.

De Schamphelaere, K.A.C., Canli, M., Van Lierde, V., Forrez, I., Vanhaecke, F. \& Janssen, C.R. 2004. Reproductive toxicity of dietary zinc to Daphnia magna. Aquat. Toxicol. 70(3): 233-244. https://doi.org/10.1016/j.aquatox.2004.09.008.

Fairbairn, D.J., Karpuzcu, M.E., Arnold, W.A., Barber, B.L., Kaufenberg, E.F., Koskinen, W.C., Novak, P.J., Rice, P.J. \& Swackhamer, D.L. 2015. Sediment-water distribution of contaminants of emerging concern in a mixed use watershed. Sci. Total Environ. 505: 896-904. https://doi.org/10.1016/j. scitotenv.2014.10.046.

Imperato, M., Adamo, P., Naimo, D., Arienzo, M., Stanzione, D. \& Violante, P. 2003. Spatial distribution of heavy metals in urban soils of Naples city (Italy). Environ. Pollut. 124(2): 247-256. https://doi.org/10.1016/S0269-7491(02)00478-5.

Jensen-fontaine, M., Norwood, W.P., Brown, M., Dixon, D.G. \& Le, X.C. 2014. Uptake and Speciation of Vanadium in the Benthic Invertebrate Hyalella azteca. Environ. Sci. Technol. 48(1): 731738. https://doi.org/10.1021/es403252k.

Kimberly, D.A., Salice, C.J. 2014. If you could turn back time: Understanding transgenerational latent effects of developmental exposure to contaminants. Environ. Pollut. 184: 419-425. https:// doi.org/10.1016/j.envpol.2013.09.018.

Lima, A.R.A., Barletta, M. \& Costa, M.F. 2015. Seasonal distribution and interactions between plankton and microplastics in a tropical estuary. Estuar. Coast. Shelf Sci. 165: 213-225. https://doi. org/10.1016/j.ecss.2015.05.018.

Moreno-González, R., Rodriguez-Mozaz, S., Gros, M., Barceló, D.
\& León, V.M. 2015. Seasonal distribution of pharmaceuticals in marine water and sediment from a mediterranean coastal lagoon (SE Spain). Environ. Res. 138: 326-344. https://doi. org/10.1016/j.envres.2015.02.016.

Morris, J.M. \& Meyer, J.S. 2006. Extracellular and intracellular uptake of zinc in a photosynthetic biofilm matrix. Bull. Environ. Contam. Toxicol. 77(1): 30-35. https://doi.org/10.1007/s00128006-1028-5.

Muyssen, B.T.A. \& Janssen, C.R. 2001. Multigeneration zinc acclimation and tolerance in Daphnia magna: Implications for water-quality guidelines and ecological risk assessment. Environ. Toxicol. Chem. 20(9): 2053-2060.

National Research Council. 2007. Effectiveness of Dredging at Superfund Mega-Sites. National Academy Press. Washington, DC.

Nedrich, S.M. 2017. Metal Fate Dynamics and Ecotoxicology in Hydrologically Variable Aquatic Ecosystems. PhD Dissertation. University of Michigan, Ann Arbor, 183p.

Nedrich, S.M. \& Burton, G.A. 2017a. Indirect effects of climate change on zinc cycling in sediments: The role of changing water levels. Environ. Toxicol. Chem. 36(9): 2456-2464. https://doi. org/10.1002/etc. 3783 .

Nedrich, S.M. \& Burton, G.A. 2017b. Sediment Zn-release during post-drought re-flooding: Assessing environmental risk to Hyalella azteca and Daphnia magna. Environ. Pollut. 230: 11161124. https://doi.org/10.1016/j.envpol.2017.07.073.

Nedrich, S.M., Chappaz, A., Hudson, M.L., Brown, S.S. \& Burton, G.A. 2018. Biogeochemical controls on the speciation and aquatic toxicity of vanadium and other metals in sediments from a river reservoir. Sci. Total Environ. 612: 313-320. https://doi. org/10.1016/j.scitotenv.2017.08.141.

Nouira, T., Risso, C., Lassaad, C., Budzinski, H. \& Boussetta, H. 2013. Chemosphere Polychlorinated biphenyls (PCBs) and Polybrominated Diphenyl Ethers (PBDEs) in surface sediments from Monastir Bay (Tunisia, Central Mediterranean): Occurrence, distribution and seasonal variations. Chemosphere. 93(3): 487493. https://doi.org/10.1016/j.chemosphere.2013.06.017.

Pose-Juan, E., Sánchez-Martín, M.J., Andrades, M.S., RodríguezCruz, M.S. \& Herrero-Hernández, E. 2015. Pesticide residues in vineyard soils from Spain: Spatial and temporal distributions. Sci. Total Environ. 514: 351-358. https://doi.org/10.1016/j. scitotenv.2015.01.076.

Remaili, T.M., Simpson, S.L., Amato, E.D., Spadaro, D.A., Jarolimek, C. V. \& Jolley, D.F. 2016. The impact of sediment bioturbation by secondary organisms on metal bioavailability, bioaccumulation and toxicity to target organisms in benthic bioassays: Implications for sediment quality assessment. Environ. Pollut. 208: 590-599. https://doi.org/10.1016/j. envpol.2015.10.033.

Wilkinson, J.L., Hooda, P.S., Swinden, J., Barker, J. \& Barton, S. 2017. Spatial distribution of organic contaminants in three rivers of Southern England bound to suspended particulate material and dissolved in water. Sci. Total Environ. 593-594: 487-497. https://doi.org/10.1016/j.scitotenv.2017.03.167.

Wu, Q., Xia, X., Mou, X., Zhu, B., Zhao, P. \& Dong, H. 2014. Effects of seasonal climatic variability on several toxic contaminants in urban lakes: Implications for the impacts of climate change. J. Environ. Sci. (China). 26(12): 2369-2378. https://doi. org/10.1016/j.jes.2014.04.001. 